\title{
Maternal outcome in Pih Patients in Relation with Serum IDH Levels
}

\author{
Dr. Urvashi Sharma, Dr. C. Hariharan.
}

\section{Introduction}

Pregnancy is a physiological state associated with many alterations in the metabolic, biochemical, physiological, hematological and immunological process. If there are no complications, all these changes are reversible in few days to months after delivery. Hypertension during pregnancy is a major health problem being a leading cause of maternal, fetal \& perinatal morbidity and mortality. Fifty percent of women diagnosed with gestational hypertension between 24 and 35 weeks develop preeclampsia (PE). Pre-eclampsia is a multi-system disorder of unknown etiology, unique to pregnancy, with onset after 20 weeks of gestation. Preeclampsia remains poorly characterized with regard to pathophysiology involved in the development of hypertensive disease in pregnancy. It has been described as a two stage disease in which stage I is heralded by poor placental invasion, development, and remodeling. Stage II develops later and involves the clinical recognition of preeclampsia in the form of maternal hypertension, proteinuria, and end-organ disease. Mild preeclampsia occurs in approximately $15 \%$ of pregnancies, moderate to severe preeclampsia in around $8 \%$ and severe preeclampsia in about $1 \%$ to $2 \%$. Preeclampsia is a syndrome, which affects virtually all-maternal organ systems. There is increasing evidence that endothelial cell and altered endothelial cell function play an important role in the pathogenesis of preeclampsia. LDH is most often measured to evaluate the presence of tissue damage. The enzyme LDH is in many body tissues, especially heart, liver, kidney, skeletal muscle, brain, blood cells, and lungs. Dysfunction of endothelial cells can contribute to inappropriate vasoconstriction and platelet aggregation which are early signs of atherosclerosis, hypertension and coronary vasospasm. Acute clinicalsymptoms that danger fetus life in preeclampsia correlate with distinct activity of AST and LDH. ${ }^{1} \mathrm{LDH}$ is the earliest marker seen in blood during hypoxia and oxidative stress. It is a useful biochemical marker that reflects the severity of and the occurrence of complications of PE \& E.; these are preventable if identified at an early stage and adequately managed. LDH test is easily available, cheap and with good diagnostic \& prognostic value. High serum levels of LDH correlate well with the severity of the disease and poor outcomes in PE \& E.' we conducted this study with the aim to estimate level of LDH in normotensive patients, mild preeclampsia patients, severe preeclampsia patients and to find its correlation with maternal outcome.

\section{Materials And Methods}

This study was conducted in the Department of Obstetrics and Gynecology, Acharya Vinobha Bhave Rural Hospital (AVBRH) at Sawangi (Meghe), Wardha, Maharashtra, India.Ethical Clearance was taken from the ethical committee of Jawaharlal Nehru Medical College (JNMC), Sawangi, (Meghe), Wardha. Prospective case control comparative study was conducted over total 300 subjects, comprising of 100 with mild preeclampsia, 100 with severe preeclampsia and 100 normotensive pregnant controls.

All eligible pregnant women $\geq 20$ weeks of gestation were enrolled in this study and divided into following groups:

- Group 1-Healthy normotensive (Normal) pregnant women (Controls no.=100)

- Group-2 - Patients of preeclampsia and eclampsia (Total no.=200)

- Group 2 subjects was further subdivided into 2 subgroups -

- Subgroup 2A- Mild Preeclampsia (Total no.=100)

- Subgroup 2B - Severe Preeclampsia (Total no.=100)

\section{Refined selection criteria -}

- Sub group 2A- Mild preeclampsia - Defined as Pregnant female of $\geq 20$ weeks of gestation with blood pressure $\geq 140 / 90 \mathrm{~mm}$ of $\mathrm{Hg} \&<160 / 110 \mathrm{~mm}$ of $\mathrm{Hg}$ noted first time during pregnancy on $\geq 2$ occasions at least 6 hours apart with proteinuria of $\geq 1+(\geq 30 \mathrm{mg} / \mathrm{dl})$ by dipstick method in a random urine sample, would be considered as having mild preeclampsia after excluding urinary tract infection.

- Sub group 2B-Severe preeclampsia - Defined as the presence of one of the following symptoms or signs:

- Systolic Blood Pressure of $160 \mathrm{~mm} \mathrm{Hg}$ or higher or Diastolic Blood Pressure of $110 \mathrm{~mm} \mathrm{Hg}$ or higher on 2 occasions, at least 6 hours apart, while the patient is resting.

- Proteinuria of $5 \mathrm{~g}$ or higher in a 24 -hour urine specimen or $3+$ or greater on two random urine samples collected at least 4 hours apart. 
- Oliguria of less than $500 \mathrm{ml}$ in 24 hours.

- Cerebral or visual disturbances.

- Pulmonary edema or cyanosis.

- Epigastric or right upper quadrant pain.

- Impaired Liver function.

- Thrombocytopenia (platelets <100000/-).

- Intrauterine growth restriction.

Blood samples for serum lactate dehydrogenase levels were collected from preeclamptic cases in plain bulb with aseptic conditions, at the time of diagnosis and before start of treatment. These were analyzed at and by the Department of Pathology and biochemistry Acharya Vinoba Bhave Rural Hospital (AVBRH) at Sawangi (Meghe), Wardha, Maharashtra, with established spectrophotometric pyruvate method, where conversion of pyruvate to lactate takes place in the presence of NADH by the action of lactate dehydrogenase.

\section{Observations And Result}

Table No 1: Showing Age-Wise Distribution of the Groups (Mild Preeclampsia, Severe Preeclampsia and Controls) $(\mathrm{N}=300)$

\begin{tabular}{|l|l|l|l|l|}
\hline \multirow{2}{*}{ Age } & Groups & \multirow{2}{*}{ Total } \\
\cline { 2 - 5 } & Mild Preeclampsia & Severe Preeclampsia & Control & \\
\hline$<20$ Years & $13(4.3 \%)$ & $13(4.3 \%)$ & $13(4.3 \%)$ & $39(13 \%)$ \\
\hline $21-30$ Years & $79(26.3 \%)$ & $80(26.6 \%)$ & $83(27.6 \%)$ & $242(80 \%)$ \\
\hline $31-40$ Years & $7(2.3 \%)$ & $5(1.6 \%)$ & $4(1.3 \%)$ & $16(5.3 \%)$ \\
\hline$>40$ Years & $1(0.3 \%)$ & $2(0.6 \%)$ & 0 & $3(1 \%)$ \\
\hline Total & $\mathbf{1 0 0}$ & $\mathbf{1 0 0}$ & $\mathbf{1 0 0}$ & $\mathbf{3 0 0}$ \\
\hline
\end{tabular}

Table No 2: Showing Parity-Wise Distribution Of Patients \& Controls (N=300)

\begin{tabular}{|l|l|l|l|l|}
\hline \multirow{2}{*}{ Parity } & Groups & \multirow{2}{*}{ Total } \\
\cline { 2 - 5 } & Mild Preeclampsia & Severe Preeclampsia & Control & \\
\hline Primigravida & $50(16.6 \%)$ & $59(19.6 \%)$ & $58(19.3 \%)$ & $167(55.6 \%)$ \\
\hline Secondary Gravida & $42(14 \%)$ & $35(11.6 \%)$ & $35(11.6 \%)$ & $112(37.3 \%)$ \\
\hline Multigravida & $8(2.6 \%)$ & $6(2 \%)$ & $7(2.3 \%)$ & $21(9 \%)$ \\
\hline Total & 100 & 100 & 100 & 300 \\
\hline
\end{tabular}

Table no 3: showing distribution of ldh levels in patients and control groups.

\begin{tabular}{|l|l|l|l|l|}
\hline \multirow{2}{*}{ LDH } & \multicolumn{2}{|l|}{ GROUPS } & \multirow{2}{*}{ TOTAL } \\
\cline { 2 - 4 } & Mild Preeclampsia & Severe Preeclampsia & Control & \\
\hline$<600$ IU & $50(16.66 \%)$ & $5(1.6 \%)$ & $98(32.66 \%)$ & $153(51 \%)$ \\
\hline $\mathbf{6 0 0 - 8 0 0}$ IU & $41(13.6 \%)$ & $19(6.3 \%)$ & $1(0.3 \%)$ & $61(20.3 \%)$ \\
\hline$>\mathbf{8 0 0}$ IU & $9(3 \%)$ & $76(25.3 \%)$ & $1(0.3 \%)$ & $86(28.6 \%)$ \\
\hline Total & 100 & 100 & 100 & 300 \\
\hline
\end{tabular}

Table No 10: Showing Maternal Complications According To Ldh In Severe Preeclampsia Group (N=100)

\begin{tabular}{|l|l|l|l|l|l|}
\hline Complications & $<600 \mathrm{Iu}$ & $600-800 \mathrm{Iu}$ & $>800 \mathrm{Iu}$ & Total & P Value \\
\hline Dic & $1(1 \%)$ & $1(1 \%)$ & 0 & $2(2 \%)$ & 0.006 \\
\hline Eclampsia & $1(1 \%)$ & 0 & $4(4 \%)$ & $5(5 \%)$ \\
\hline Wound Gape & 0 & 0 & $4(4 \%)$ & $4(4 \%)$ \\
\hline Shock & 0 & 0 & $2(2 \%)$ & $2(2 \%)$ \\
\hline Pph & 0 & 0 & $2(2 \%)$ & $2(2 \%)$ \\
\hline Arf & $1(1 \%)$ & 0 & $10(10 \%)$ & $11(11 \%)$ \\
\hline Hellp & $1(1 \%)$ & $2(2 \%)$ & $7(7 \%)$ & $10(10 \%)$ \\
\hline Abruption & 0 & 0 & $3(3 \%)$ & $3(3 \%)$ & \\
\hline
\end{tabular}

\section{Results}

In this study out of total 300 patients $39(13 \%)$ patients were in age group of less than 20 years, 242 $(80 \%)$ patients were in age group between 21-30 years, $16(5.3 \%)$ patients were in age group of 31-40 years and $3(1 \%)$ patients were in age group of more than 40 years. In this study out of total 300 patients $167(55.6 \%)$ patients were primigravida, $112(37.3 \%)$ patients were secondary gravida and $21(9 \%)$ patients were multigravida. In this study out of 300, in mild preeclampsia group 50(16.66\%) patients had LDH value less than $600 \mathrm{IU}, 41(13.6 \%)$ patients had $\mathrm{LDH}$ value between 600-800 IU and $9(3 \%)$ patients had LDH values of more than 800 IU. In severe preeclampsia group 5 (1.6\%) patients had LDH value of less than 600 IU, $19(6.3 \%)$ patients had LDH value between $600-800$ IU and 76 (25.3\%) patients had LDH value more than 800 IU. In 
control group 98 (32.66\%) patients had LDH value less than $600 \mathrm{IU}, 1(0.3 \%)$ patient had LDH value between $600-800 \mathrm{IU}$ and $1(0.3 \%)$ patient had LDH value of more than $800 \mathrm{IU}$.

In the present study, in the group of severe preeclampsia $2 \%(2)$ patient went into DIC with LDH levels being >600, 600-800 IU respectively, 5\% (5) patient developed eclampsia out of which $1 \%(1)$ had LDH level less than $600 \mathrm{IU}$ and $4 \%(4)$ had LDH levels more than $800 \mathrm{IU} .4 \%(4)$ of patient developed wound gape all of them had LDH levels more than 800 IU. $2 \%$ (2) of patient went into shock LDH level in these patient were $>800$ IU. $2 \%$ (2) patient went into post partumhaemorrhage LDH levels for these patients were observed as more than 800 IU. 11\% (11) patient developed acute renal failure $1 \%$ (1) of patient had LDH level less than 600 IU, $10 \%(10)$ of patient developed acute renal failure had LDH level more than 800 IU. 10\% (10)of patient developed HELLP 1\%(1),2\%(2) and 7\%(7) patient had LDH levels as less than 600. 600-800 and more than 800 IU.3\% (3) patients developed abruption had LDH levels more than $800 \mathrm{IU}$.

\section{Discussion}

Preeclampsia is considered to be an idiopathic multisystem disorder that is specific to human pregnancy.Complex cellular toxic endocrinological mechanisms are believed to be responsible for cell destruction leading to multi-organ dysfunction Error! Bookmark not defined..In India, Pregnancy induced hypertension is seen mostly in younger age group and in primigravida women. Preeclampsia is primarily regarded as a disease of first pregnancy.${ }^{19}$ Preeclampsia may be life-threatening for both mother and child, increasing both fetal and maternal morbidity and mortality. As women with severe preeclampsia have about 5 fold increase in perinatal mortality and morbidity.

Hence, need has been felt for an inexpensive, easily available biomarker enabling early identification of preeclampsia, which in turn can predict severity and outcome, can be very helpful in lowering the maternal and fetal morbidity and mortality. It should help to identify high risk groups early in pregnancy, so that preventive measures can be instituted without delay to reduce maternal \& fetal morbidity and mortality

Earlier studies have suggested possible role of Serum Lactic dehydrogenase (LDH) in the pathogenesis of preeclampsia. Elevated levels of serum LDH indicate the tissue damage related to endothelial dysfunction and endovascular which are main causes of occurrence of preeclampsia.Therefore, serum LDH level seems promising, as it fulfilsmost criteria for an ideal biomarker, because it is inexpensive, widely available, and it is quickly estimable.

In the present study, mean ages among mild preeclampsia, severe preeclampsia and control groups were $25+5$ years, $25+5.41$ years and $24+3.45$ years respectively. Subjects in both groups were almost of equal age groups, and $50(50 \%)(50 / 100)$ patients were primigravida in mild preeclampsia, and $59(59 \%)(59 / 100)$ patients were primigravida in severe preeclampsia group $58(58 \%)(58 / 100)$ patients were primigravida in the control group. Young age and primigravidity are well-known risk factors for developing pre-eclampsia, ,. The patients with severe pre-eclampsia in our study were significantly younger and with significant low gravidity and parity compared with the normotensive and mildly pre-eclamptic women.

This is consistent with other studies. In the study conducted by Sajith et al ${ }^{19}$ the incidence of hypertension in pregnancy was highest among primigravidae. 53.8\% (56/104) were primigravida and 46.2\% (48/104) were multigravida. Several other authors Aabidha et al, Chan P et al and Mjahed K et al have reported primiparity in $52-73 \%$ patients of preeclampsia.

The most important finding in present study was the high frequency of high levels of serum LDH levels in the study population, the mean LDH value was $618.48+-169.65 \mathrm{IU}, 1046.45+-648.49$ IU both in mild preeclampsia and severe preeclampsia groups respectively.50 patients in mild preeclampsia group and 5 patients in severe preeclampsia group had LDH levels less than $600 \mathrm{IU}$ ie. in normal range. There is significant rise in the LDH levels with the increasing severity of the disease (172.37 \pm 28.09$)$ normotensive, $(356.33 \pm 24.47)$ mild preeclampsia, $(609.91 \pm 136.92)$ severe preeclampsia and $(854.05 \pm 247.45)$, eclampsia $(\mathrm{P}<0.0001)$. it was also observed by Malvino et al ,samara et al

In the present study, study group had more cesarean sections $37 \%(74 / 200)$ than vaginal deliveries $63 \%(126 / 200)$ as compared to control group who had $13 \%$ cesarean sections (13/100) and 87\% (87/100) vaginal deliveries. Though the levels of LDH were low in subject group who underwent cesarean section in view of scar tenderness/ impending scar dehiscence, no relation was found with LDH and cesarean sections for impending scar dehiscence.In present study, the main indication for cesarean deliveries in study group was impending eclampsia $22(7.3 \%)$, fetal distress $30(10 \%)$, abruption $6(2 \%)$, placenta previa $3(1 \%)$ and previous LSCS with impending scar dehiscence 13(4.3\%) Higher serum LDH levels were associated with increased incidence of maternal complications like abruption placenta, renal failure HELLP syndrome, PPH etc. in the present study. There was a significant increase in maternal morbidity with increasing serum LDH levels $(\mathrm{P}=0.00)$. Maternal morbidity was $13 \%$ in patients in study group and this was a significant rise $(\mathrm{P}=0.00)$ which was comparable with other study of Hussein et al 
Severely pre-eclamptic women with LDH levels of 800 IU/l showed a significant increase in complications in terms of eclampsia, abruption placenta and various other complications compared to women who had lower serum LDH levels, in the study of Qublan et al A high serum level of LDH ([1,400 IU/l) were shown to have a high predictive value for significant maternal morbidity in a study conducted by Martin et ${ }^{\text {al }}$ Error! Bookmark not defined. Catanzerite et al. reported a subgroup of patients who had elevated levels of LDH manifested with hemolysis, elevated liver enzymes, low platelet count (HELLP) syndrome and were at a high risk for developing maternal mortality. Demiretal.concluded that there was a statistically significant relation between maternal complications and high LDH levels. It was noted that in early onset severe preeclampsia, LDH levels before delivery were significantly higher in the abruption group Odendaal et al..

\section{Conclusions}

LDH levels are consistently and reliably elevated in PE and E.LDH levels correlate well with the disease severity.LDH levels also correlate reliably with maternal outcomesLDH levels can be a used as a good predictor to identify the high risk patients to improve maternal outcomes. In the meantime, all cases of PE and Eclampsia should be mandatorily screened and risk stratified with LDH estimation. High risk cases with LDH beyond 600/1U should be segregated for management at a higher center

\section{References}

[1]. Lincy Joseph, Mathew George, Anju Alex. A review on estimation of Serum LDH and Uric acid in hypertensive vs normal pregnant woman and its correlation with maternal outcome in tertiary hospital. Int J Therapeutic Appl, Vol 32, 2016, 35-37.

[2]. Barton JR, O'brien JM, Bergauer NK, Jacques DL, Sibai BM. Mild gestational hypertension remote from

[3]. Ian Donald RenuMisra MS, editor - Ian Donald's Practical Obstetric Problem.6 ${ }^{\text {th }}$ Edition.New Delhi. BI Publications Pvt Ltd;2012.Chapter:Hypertensive Disorders in Pregnancy:281-309

[4]. Roberts JM, Gammill HS. Preeclampsia: recent insights. Hypertension. 2005;46(6):1243-1249.

[5]. Jan AK, Jamil M. Management of Pre-Eclampsia and Eclampsia. JPMI 2000; 14(1): 7-19.

[6]. Pasaoglu H, Bulduk G, Ogus E, Pasaoglu A, Onalan G. Nitric oxide, lipid peroxides, and uric acid levels

[7]. in pre-eclampsia and eclampsia. Tohoku J Exp Med 2004; 202(2): 87-92.

[8]. Malarewicz A, Gruszka O, Szymkiewicz J, Rogala J. The usefulness of routine laboratory tests in the evaluation

[9]. of sudden threat of pregnant woman and fetus in pre-eclampsia. Ginekol Pol 2006; 77(4): $276-84$

[10]. Dave A, Maru L, Jain A. LDH (Lactate Dehydrogenase): A biochemical marker for the prediction of adverse outcomes in preeclampsia and eclampsia. J ObstetGynaecol India 2016 Feb:66(1):23-9.

[11]. Jaiswar SP, Gupta A, Sachan R, Natu SN, Shaili M, Lactic dehydrogenase: A biochemical marker for Preeclampsia-Eclampsia. J ObstGynInd (Nov-Dec 2011) 61(6):645-648

[12]. Rubina Aziz TabassumMahboob ARYA Atherosclerosis Journal 2008, 4(1): 29-32

[13]. S. M. Munde, N. R. Hazari, A. P. Thorat, S. B. Gaikwad, V. S. Hatolkar, Gamma GlutamylTransferase and Lactate Dehydrogenase as Biochemical Markers of Severity of Preeclampsia, http://waset.org/publications/9997667/gamma-glutamyl-transferase-and-lactatedehydrogenase-as-biochemical-markers-of-severity-of-preeclampsia

[14]. Robillard PY, Dekker GA, Hulsey TC: Revisiting the epidemiological standard of preeclampsia: primigravidity or primipaternity? EurJObstetGynecolReprodBiol, 1999: 84: 37-41

[15]. Lopez-Jaramillo P, Casas JP, Serrano N: Preeclampsia: from epidemiological observation to molecular mechanisms. Brazil J Med BiolRes, 2001; 34: 1227-35

[16]. Magann EF, Martin JN: Twelve steps to optimal management of HELLP

[17]. syndrome. ClinObestetGynecol, 1999; 42: 532-50

[18]. Aabidha PM, Cherian AG, Paul E, Helan J. Maternal and fetal outcome in pre-eclampsia in a secondary care hospital in South India. Journal of family medicine and primary care.2015;4(2):257.

[19]. Chan P, Brown M, Simpson JM, Davis G. Proteinuria in pre-eclampsia: how much matters? BJOG: An International Journal of Obstetrics \&Gynaecology. 2005;112(3):280-285.

[20]. Mjahed K, Alaoui SY, Barrou L. Acute renal failure during eclampsia: incidence risks factors and outcome in intensive care unit. Renal failure.2004;26(3):215-221

[21]. Liggy Andrews, Nikunj Patel Int J Res Med Sci. 2016; 4(5): 1347-1350 doi: 10.18203/2320 6012.ijrms20161112 Correlation of serum lactate dehydrogenase and pregnancy induced hypertension with its adverse outcomes

[22]. Malvino E, Munoz M, Ceccotti C, Janello G, McLounghlin D, Pawlak P, et al. Maternal morbidity and perinatal mortality in HELLP syndrome, multicentric studies in intensive care units Buenos Aires area. Medicina (B. Aires). 2005;65(1):17-23.

[23]. Sarmah J. Evaluation of serum aspartate aminotransferase (AST), alanine aminotransferase (ALT), alkaline phosphatase (ALP), lactate dehydrogenase (LDH) and uric acid in preeclampsia.IOSR Journal of Dental and Medical Sciences. 2015;14(6):10-12.

[24]. Catanzerite VA, Steinberg SM, Mosley CA, et al. Severe preeclampsia with fulminant and extreme elevation of aspartate aminotransferase and lactate dehydrogenase levels. Am J Perinatol. 1995;12:310-3.

[25]. Odendaal HJ, Pattinson RC, Bam R, Grové D, Kotze TJ. Aggressive or expectant management for patients with severe preeclampsia between 28-34 weeks gestation: a randomised controlled trial. ObstetGynecol1990; 76: 1070-1075 